\title{
Indústria e Desenvolvimento Econômico:

\section{PROGRAMA COMPETITIVIDADE INDUSTRIAL REGIONAL (PCIR) DE MINAS GERAIS: DAS CONSULTORIAS DE LEAN AOS DESAFIOS DA INDÚSTRIA 4.0}

\author{
Simone Porto ${ }^{1}$ \\ Andréa de Oliveira Silva ${ }^{2}$ \\ Alan Senra Cheib ${ }^{3}$ \\ Raquel Lopes ${ }^{4}$
}

\section{Resumo:}

Este artigo apresenta o Programa de Competitividade Industrial Regional (PCIR) do sistema FIEMG, que foi planejado para o período de 2013-2033. A metodologia de construção e monitoramento do projeto é apresentada, bem como os resultados parciais alcançados até Dezembro de 2017. Um estudo de caso sobre a execução do PCIR no setor sucroenergético do Triângulo Mineiro ilustra a atuação regional do programa e as perspectivas de enfrentamento dos desafios nos próximos anos.

\section{Palavras-chave:}

Competitividade, Desenvolvimento Regional, Inovação, Indústria e Desenvolvimento Setorial.

\section{Abstract:}

This paper presents the Regional Industrial Competitiveness Program (PCIR) of the FIEMG system, which was planned for the period 2013-2033. The project's construction and monitoring methodology is presented, as well as the results achieved until the December of 2017. A case of study of the implementation of the PCIR in the sugar cane sector of the "Triângulo Mineiro region" illustrates the regional performance of the program and the perspectives of confronting the industry challenges in the coming years.

Keywords: Competitiviness, Regional-Development, Innovation, Industry and Sectoral Development.

Classificação JEL: R120 Size and Spatial Distributions of Regional Economic Activity

Classificação ENEI: 1.3 Crescimento, produtividade e competitividade.

\footnotetext{
${ }^{1}$ Gerente de Projetos do Instituto Euvaldo Lodi//Minas Gerais.

${ }^{2}$ Analista de Projetos do Instituto Euvaldo Lodi//Minas Gerais.

${ }^{3}$ Analista de Projetos do Instituto Euvaldo Lodi//Minas Gerais.

${ }^{4}$ Coordenadora de Projetos do Instituto Euvaldo Lodi//Minas Gerais.
} 


\section{INTRODUÇÃO}

Atualmente a produção setorial concentrada em mesma localidade é considerada um aspecto importante para promover o desenvolvimento econômico e industrial, devido às experiências bem-sucedidas de desenvolvimento de capacitações produtivas e empresariais existentes neste tipo de organização da produção.

O referencial sobre Arranjos Produtivos Locais (APLs), por exemplo, analisa as características de segmentos industriais e instituições de um mesmo setor que estão localizadas em uma mesma região e que conseguem, a partir de tal concentração, promover ganhos de mercado e obter vantagens como melhor acesso a fornecedores, baixos custos de transporte, encadeamento interindustrial e desenvolvimento/melhoria de produtos de acordo com a demanda, por exemplo.

Atualmente o estado de Minas Gerais apresenta total de 39 Arranjos Produtivos Locais reconhecidos pela Secretaria Extraordinária de Desenvolvimento Integrado e Fóruns Regionais (SEEDIF), e desde a década de 1990, essa forma de organização produtiva territorial tem ganhado destaque nas estratégias das entidades governamentais e das instituições públicas e privadas de pesquisa, prestação de serviço e apoio aos setores mineiros.

Este artigo apresenta outra abordagem de alcance estadual, o Programa de Competitividade Industrial Regional (PCIR), um projeto da Gerência de Projetos para a Indústria (GPI) do Instituto Euvaldo Lodi, sistema FIEMG, que foi planejado no período de 2013-2015, está em fase de execução desde 2016 e tem seu encerramento previsto para 2033. Ele conta com o apoio e colaboração do sistema FIEMG e de diferentes instituições públicas e privadas de Minas Gerais. Além disso, ele está alinhado à diretriz estratégica do Sistema FIEMG, e todas as suas atividades seguem a metodologia e processos do IEL/MG, que por sua vez, segue as boas práticas preconizadas pelo PMBOK.

O principal objetivo do PCIR é contribuir para a competitividade industrial em Minas Gerais, por meio de ações de curto, médio e longo prazo voltado para setores industriais de todas as regiões do estado. Ele analisa as características e desafios de cada setor, considerando duas premissas: a) seu papel para a economia de sua região, independente de existir, ou não, todos os elos da sua cadeia na mesma localidade; b) a importância de cada setor para a economia do Estado. Nesse cenário, o PCIR contempla tanto setores organizados em APLs, como aqueles cujas atividades a montante e jusante não estão situadas em uma mesma região.

Além dessa introdução e Referências Bibliográficas, o artigo está dividido em quatro seções. A seção de Referencial Teórico discorre brevemente sobre algumas características de Arranjos Produtivos Locais, destacando um fator que, de maneira geral, representou obstáculo para o seu sucesso nos últimos anos, e que é trabalhado no PCIR. Além disso, essa seção analisa quatro aspectos fundamentais para a constituição e execução do Programa de Competitividade Industrial Regional.

A seção de Metodologia apresenta todos os processos envolvidos na estruturação do PCIR, segundo a ferramenta de Gestão de Projetos, e detalha etapas e atividades envolvidas, principalmente no processo de Planejamento. Já a seção de Resultados está dividida em duas subseções: enquanto a primeira apresenta os resultados gerais obtidos pelo programa no período de 2016-2018, destacando os principais desafios e o mecanismo utilizado para enfrentá-los; a segunda subseção descreve resultados obtidos a partir da execução de ações para o setor sucroenergético do Triângulo Mineiro, que é um dos setores contemplados pelo programa. Por fim, a seção de Conclusão retoma os principais aspectos que estão possibilitando a execução do PCIR, destaca seus desafios e os resultados obtidos por meio da atuação Instituto Euvaldo Lodi junto às empresas de Minas Gerais. 


\section{CONSIDERAÇÕES SOBRE ESTRATÉGIAS DE DESENVOLVIMENTO SETORIAL EM MINAS GERAIS}

Nas últimas décadas, algumas instituições e entidades de Minas Gerais têm apresentado importantes programas e iniciativas voltados ao desenvolvimento socioeconômico e industrial do estado. Essa seção apresenta, primeiramente, uma breve análise sobre algumas características e desafios dos programas voltados para Arranjos Produtivos Locais, instituído principalmente a partir de meados dos anos 2000. Posteriormente, a seção apresenta e analisa o Programa de Competitividade Industrial Regional (PCIR), atualmente em execução em várias regiões do estado de Minas Gerais.

Os Arranjos Produtivos Locais podem ser definidos como 'aglomeração de empresas, localizadas num mesmo território, que apresentam especialização produtiva e mantêm vínculos de articulação, interação, cooperação e aprendizagem entre si e com outros atores locais como o governo, associações empresariais, instituições de crédito, ensino e pesquisa' (CARDOSO et al, 2014, p.7). Entre as principais características dos APLs destaca-se a capacidade de gerar economias externas, incidentais ou deliberadas, que contribuem para o aumento da competitividade das empresas do arranjo produtivo local.

As economias externas incidentais são benefícios decorrentes da existência local de um conjunto de mão de obra especializada e de fornecedores de todos os elos da cadeia, bem como da presença de ambiente interno que incentiva a troca de informações sobre produtos e processos. Já as economias externas deliberadas referem-se à benefícios tais como compra compartilhada de matérias primas, promoção de cursos de capacitação gerencial e formação profissional, criação de consórcios de exportação, contratação de serviços especializados, estabelecimento de centros tecnológicos de uso coletivo, cooperativas de crédito, entre outros mecanismos que facilitam o acesso a novas tecnologias e mercado (SUZIGAN et al, 2003).

Os agentes de cada APL atuam em diversos subsistemas - produção, logística e distribuição, comercialização, desenvolvimento tecnológico e centros de prestação de serviços - onde os fatores econômicos, sociais, culturais e institucionais estão fortemente entrelaçados (SUZIGAN, 2006, p. 3), repercutindo em suas condições competitivas dentro do APL. Além disso, cada APL apresenta características específicas em relação à sua formação, evolução e organização institucional, que impactam na organização e estruturas produtivas, nos relacionamentos e articulação entre empresas e instituições e na forma de governança local, pública ou privada.

A governança de um APL é o conjunto de representantes de entidades e empresas locais que apresentam modos de coordenação, intervenção e participação nos processos de decisão locais, contribuindo para a descentralização e repartição do poder e a acomodação de interesses, garantindo assim a realização de ações coletivas (JACOMETI et al, 2016, p. 435; CONEJERO, 2017, p. 282). A principal função da governança local é a coordenação e alinhamento entre diferentes iniciativas, observando as características e especificidades de sua localidade, assim como os prazos, distribuição de atividades e responsabilidades e o grau de comprometimento dos agentes participantes do APL (JACOMETI et al, 2016, p. 435). Nesse sentido, a governança é um ente de grande importância para o funcionamento e desempenho de cada APL.

Vale notar que a governança de cada Arranjo Produtivo Local e as instituições e instâncias do governo (federal, estadual e local) e de agências não governamentais (Sebrae, Apex, IEL e outros) podem apresentar grandes contribuições para o desenvolvimento e ganhos econômicos de empresas organizadas em APLs. Entretanto, nas últimas décadas algumas iniciativas voltadas para APLs não conseguiram alcançar 
todos os objetivos almejados por empresas e segmentos industriais (CONEJERO et al, 2017).

Até meados de 2000, alguns estados participantes de programas de APLs não apresentavam políticas públicas estruturadas visando desenvolvimento regional de longo prazo ou seus programas apresentaram descontinuidade ou interrupções, o que dificultava o alcance de resultados mais efetivos. Em alguns casos, as ações voltadas para APLs também careciam de maior articulação e coordenação, inclusive com governo estadual e federal, e não apresentavam uma visão sistêmica que promovesse encadeamentos da estrutura industrial com outros elos da economia como agroindústria, serviços e comércio, o que resultou na incapacidade de multiplicar os esforços e na dispersão de recursos (TASTCH, 2017; SUZIGAN, 2006, p. 1).

Particularmente no estado de Minas Gerais, as políticas voltadas para a APLs tiveram seu auge em meados dos anos 2000, por conta de iniciativas e programas apoiados por instituições do sistema $\mathrm{S}$, particularmente IEL e SEBRAE, com recursos de bancos como o Banco Interamericano de Desenvolvimento (BID). Entretanto, não havia uma política de desenvolvimento estadual voltada para APLs (regional) condizente ou articulada com programas do sistema $S$, o que dificultou a coordenação e execução de algumas medidas (IEL, 2014). Na prática, houve uma evolução da forma de atuação de tais entidades, acompanhando a evolução do programa, mas foram identificadas algumas dificuldades de articular algumas ações às prioridades estratégicas de cada entidade. Em alguns casos, os programas não apresentaram objetivos tão alinhados entre si e com a lógica do projeto e identifica-se a falta de convergência e articulação de interesses entre governança local e demais envolvidos na execução dos programas de apoio a APLs (IEL, 2014).

Desse modo, apesar dos Arranjos Produtivos Locais já apresentarem inúmeras características favoráveis ao desenvolvimento econômico e industrial (relacionadas à proximidade geográfica entre agentes), aspectos da governança local e da articulação entre os agentes em nível regional e estadual (via políticas públicas) também devem ser abarcados e alinhados entre entidades participantes de cada programa.

Além disso, cada setor apresenta distintas condições competitivas e tecnológicas assim como diferentes encadeamentos inter e intraindústria que devem ser considerados nos programas e iniciativas de desenvolvimento setorial localizado, a fim de promover melhores resultados, de acordo com características e demandas de cada setor. Nesse cenário, observa-se que as políticas para aglomerações industriais podem ser alinhadas e trabalhadas em conjunto com outros programas e iniciativas de desenvolvimento industrial que considerem especificidades setoriais entre as regiões do estado.

O Programa de Competitividade Industrial Regional discutido neste artigo parte da premissa de promover o desenvolvimento industrial regional de diferentes setores, considerando suas características e desafios, independentemente de suas empresas estarem localizadas geograficamente próximas ou não.

\subsection{O Programa de Competitividade Industrial Regional (PCIR)}

Atualmente os setores industriais de Minas Gerais apresentam heterogeneidade de condições que precisam ser contempladas nas estratégias e iniciativas em prol de desenvolvimento econômico do estado.

O Programa de Competitividade Industrial Regional (PCIR) é um projeto da Gerência de Projetos para a Indústria (GPI) do Instituto Euvaldo Lodi, sistema FIEMG, que foi planejado no período de 2013-2015 e que desde 2016 é executado por essa gerência, com o apoio e colaboração do sistema FIEMG e de diferentes instituições de Minas Gerais. 
O principal objetivo do PCIR é contribuir para a competitividade industrial em Minas Gerais, por meio de ações de curto, médio e longo prazo, voltadas para setores industriais, sejam os mais maduros ou aqueles mais incipientes.

O programa foi estruturado visando atendimento de grupo de setores da economia mineira e tem seguinte questão norteadora "Qual é a indústria que queremos para 2030?" Além disso, sua concepção e execução estão alinhadas à diretriz estratégica do sistema FIEMG, delineada para o período 2015-2022, que contempla os focos estratégicos Desenvolvimento e Defesa da Indústria; Tecnologia e Inovação; Segurança e Saúde no trabalho; e Educação ${ }^{5}$.

Para planejar e executar ações que contemplem as especificidades e desafios enfrentados por empresas e setores do estado de Minas Gerais, o Programa de Competitividade Industrial considera quatro aspectos: regional, setorial, institucional e temático, que são detalhados a seguir (IEL, 2014).

O primeiro aspecto relevante para a atuação do PCIR é a abrangência em todas as regiões do estado, visando mudar assim o caráter polarizado de alguns programas e iniciativas de desenvolvimento econômico industrial. A figura abaixo ilustra as 12 regiões de Minas Gerais que são atendidas pelo sistema FIEMG e são contempladas no PCIR.

\section{Figura 1 - Áreas de atuação regional do sistema FIEMG}

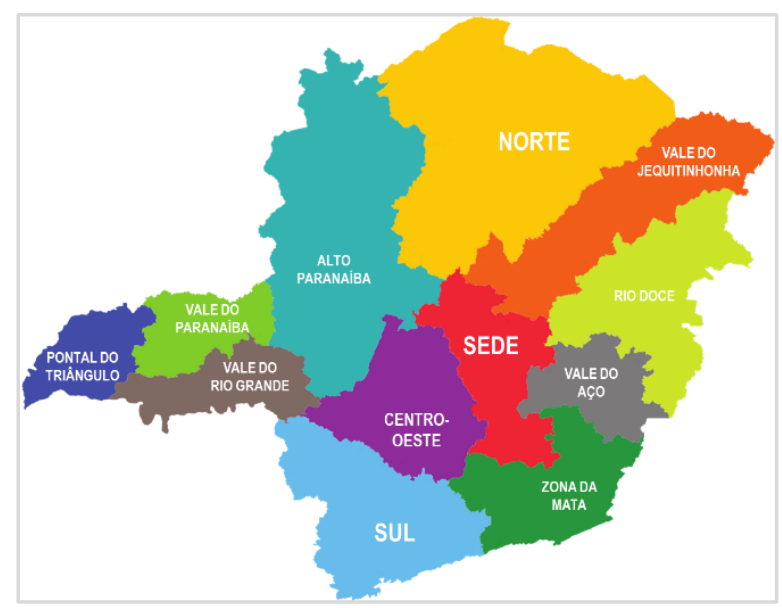

Fonte: Elaboração própria, GPI.

O segundo aspecto importante do PCIR refere-se à identificação e análise de alguns setores industriais de Minas Gerais, a partir da utilização de critério que combina resultados de tais setores para variáveis como Produtividade, Taxa de Crescimento do Valor de Transformação Industrial, Participação no emprego e Encadeamento setorial, entre outras. A partir dessa análise de tais variáveis, foi possível obter uma lista com setores que têm mais potencial para promover o desenvolvimento econômico em nível regional e estadual, seja via geração de emprego e/ou renda, por exemplo.

O terceiro aspecto relevante do programa é que ele está apoiado na premissa de que as instituições e sua governança apresentam papel muito importante para a execução e alcance de resultados das iniciativas de desenvolvimento setorial e regional. O programa parte do pressuposto de que algumas políticas adotadas em Minas Gerais nas últimas décadas apresentaram atuação pouco integrada entre atores da governança local (formada por sindicatos, empresas, instituições de ensino e pesquisa, órgãos de fomento e crédito e entidades de apoio e prestação de serviço), e isso repercutiu em desperdício de tempo e recursos; alinhamento insuficiente entre demandas e apoio; e dificuldade de alcançar os resultados esperados.

Desde o seu início em 2015, o PCIR tem considerado a governança local e eventuais dificuldades técnicas e financeiras do ambiente institucional - implícitas em

\footnotetext{
${ }^{5}$ Esses focos estratégicos serão retomados e abordados na seção de Resultados deste artigo.
} 
projetos voltados para muitos setores industriais e/ou localidades - com o propósito de responder à necessidade institucional (FIEMG) de fortalecer as governanças produtivas nas 12 regionais de sua atuação. Essa governança tem papel fundamental no modo de coordenação e organização da participação de diversos atores no processo decisório e na realização das ações coletivas para cada setor.

Nesse cenário foi criado um modelo de governança que considera os principais atores locais/regionais e tem a preocupação de estimular a participação de vários parceiros, viabilizando assim amplo diálogo entre indústria; formuladores e geradores de políticas públicas de interesse industrial; centros de pesquisa e tecnologia; entidades de apoio à indústria e universidades.

O quarto e último aspecto importante para o programa é a utilização de tipologia que agrega os principais desafios enfrentados por empresas/setores de Minas Gerais em quatro áreas temáticas: Mão de Obra e Recursos Humanos; Mercado e Produto; Tecnologia, Inovação e Modernização; Exigências Regulatórias e Sustentabilidade.

Vale registrar que os quatro aspectos mencionados nesta seção permeiam todas as etapas desde o processo de Planeamento até o Encerramento do Programa de Competitividade Industrial Regional. Entretanto, enquanto os aspectos regional, setorial e temático contribuem para o entendimento sobre a dinâmica da indústria mineira, o aspecto institucional possibilita a visão sobre o ambiente, atores e relacionamentos que são necessários para promover bons resultados para aquela dinâmica industrial.

A próxima seção descreve a Metodologia do Programa de Competitividade Industrial (PCIR), apresentando mais detalhadamente as suas principais etapas assim como os materiais gerados e fatores determinantes para a execução do programa.

\section{METODOLOGIA DO PROGRAMA DE COMPETITIVIDADE INDUSTRIAL REGIONAL}

Para conduzir o Programa de Competitividade Industrial Regional (PCIR) considerando todos esses aspectos mencionados (regional, setorial, institucional e temático) e obter os resultados esperados, utiliza-se a diretriz do guia de Gestão de Projetos, intitulado Project Management Body of Knowledge (PMBOK, 2014), que é uma abordagem relevante para conduzir programas com tal nível de complexidade (setorial e regional). Os 5 processos de Gestão de Projetos, sua duração e características principais são apresentados a seguir:

1. Iniciação (2013-2014): refere-se ao recebimento e alinhamento sobre diretrizes recebidas da presidência da FIEMG, visando a criação de um programa de competitividade que levasse em consideração setores industriais presentes em cada regional do estado de Minas Gerais;

2. Planejamento (2014-2015): abrange a identificação e reunião de informações relevantes para a proposição de ações que serão realizadas durante o projeto. Esse processo está dividido em quatro etapas: Entender, ouvir, propor e Entregar (analisados logo abaixo);

3. Execução (2016-2022): refere-se à realização de ações de acordo com o Plano de Ação, incorporando atividades como alinhamentos e articulação com governança interna (local e setorial) visando a execução, contratação e acompanhamento de ações setoriais;

4. Controle e Monitoramento (2013-2022): abrange o acompanhamento dos resultados obtidos com as ações executadas e a comunicação e articulação interna e externa;

5. Encerramento (2022): refere-se ao encerramento oficial, acompanhado por novo programa que abrangerá a atualização de setores dinamizadores de Minas Gerais e novas proposições de ações. 
Os processos de Iniciação e Planejamento ${ }^{6}$ do PCIR foram de grande relevância para a execução do programa porque nesses processos foram definidos conjunto de diretrizes e iniciativas pautadas nos aspectos regional, setorial, institucional e temático. O processo de Execução, atualmente em andamento, contempla a realização de ações voltadas para empresas de 26 setores dinamizadores e especiais existentes nas 12 regionais de atuação do sistema FIEMG. O processo de Monitoramento e Controle do PCIR, por sua vez, é realizado de maneira contínua desde o início do programa e tem sua finalização prevista para 2022, data de Encerramento do programa. É válido mencionar que todos esses processos e atividades tais como compras, trâmites gerais, contratações, gestão financeira do projeto e prestação de contas seguem e seguirão a metodologia e processos do IEL/MG, que por sua vez, segue as boas práticas preconizadas pelo PMBOK (2014).

A metodologia utilizada no processo de Planejamento do PCIR abrange 4 etapas: 1) Diagnóstico Setorial e Regional; 2) Análise de Setores mais dinâmicos; 3) Elaboração de Estratégia Setorial e Regional; e 4) Planos de Desenvolvimento Industrial Setorial, que são apresentadas a seguir.

Figura 2 - Etapas de Planejamento do Programa de Competitividade Industrial Regional

\begin{tabular}{|c|c|c|c|}
\hline $2013-14$ & & Mar a Set2015 & \\
\hline $\begin{array}{c}\text { DIAGNOSTICO } \\
\text { SETORIALE REGIONAL }\end{array}$ & & $\begin{array}{l}\text { ELABORAÇẢO DA } \\
\text { ESTRATÉGIA SETORIAL } \\
\text { E REGIONAL }\end{array}$ & \\
\hline 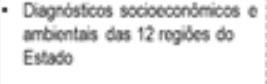 & & 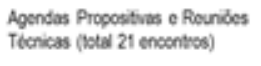 & \\
\hline - Elaborneplo de estudes sectorias & & 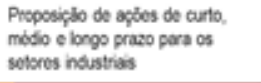 & \\
\hline $\begin{array}{l}\text { ETAPA1 } \\
\text { (ENTENDER) }\end{array}$ & $\begin{array}{l}\text { ETAPA2 } \\
\text { (OUVIR) }\end{array}$ & $\begin{array}{l}\text { ETAPA3 } \\
\text { (PROPOR) }\end{array}$ & $\begin{array}{l}\text { ETAPA4 } \\
\text { (ENTREGAR) }\end{array}$ \\
\hline & $\begin{array}{l}\text { ANÁLISE DOS SETORES } \\
\text { MAIS DINÅMICOS }\end{array}$ & & $\begin{array}{c}\text { PLANOS DE } \\
\text { DESENVOLVIMENTO } \\
\text { INDUSTRIAL REGIONAL }\end{array}$ \\
\hline & 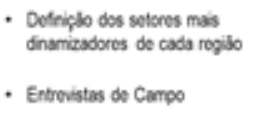 & & 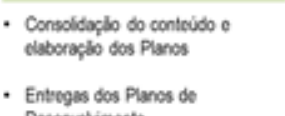 \\
\hline & $2 \cdot \operatorname{Sem} / 2014$ & & Novembro/2015 \\
\hline
\end{tabular}

Fonte: Elaboração própria, GPI.

A $1^{a}$ etapa do processo de Planejamento, realizada no período de 2013 até o $1^{\circ}$ semestre/2014, tinha o objetivo principal de entender as características de 35 setores industriais da economia mineira. E para isso, foram elaborados relatórios socioeconômicos e ambientais que consideravam as seguintes dimensões: Mapeamento Industrial; Empregos gerados; Arrecadação de ICMS; Produtividade do Trabalho; Recursos Sólidos e Hídricos; e Compreensão dos panoramas nacionais e estaduais dos setores industriais mais presentes em Minas Gerais. Já a $2^{a}$ etapa do Planejamento, ocorrida no $2^{\circ}$ semestre de 2014 , estava direcionada a identificar, dentre os 35 setores industriais do estado de Minas Gerais, aqueles que são mais dinamizadores; e a ouvir, via pesquisa empírica, quais são as características e desafios enfrentados por esses setores, considerando a perspectiva empresarial. Para identificar os setores foi utilizado um método que toma como base 5 indicadores que descrevem o desempenho e dinâmica econômica de tais setores; e foram realizadas combinações lineares dessas variáveis, de forma a construir Índice de Desempenho dos setores e assim identificar aqueles mais

\footnotetext{
${ }^{6}$ Para cumprir a proposta de discussão no tema selecionado, esse artigo abordará apenas os processos de Planejamento e Execução do Programa de Competitividade Industrial e não aprofundará em todos os aspectos e Processos da área de Gestão de Projetos.
} 
dinamizadores. A fórmula, interpretação econômica desses indicadores são apresentados no quadro a seguir.

Quadro 1 - Variáveis utilizadas na análise e seleção final de setores industriais (PCIR)

\begin{tabular}{|c|c|c|}
\hline Indicador & Fórmula & Interpretação econômica \\
\hline $\begin{array}{l}\text { Produtividade } \\
\text { do Trabalho }\end{array}$ & VTI / PO & $\begin{array}{l}\text { - Relação entre o Valor da Transformação Industrial (VTI) e a } \\
\text { População Ocupada (PO). } \\
\text { - Permite medir a participação relativa do trabalho, ou do } \\
\text { capital, no processo de desenvolvimento produtivo do estado } \\
\text { de MG. } \\
\text { - Também mede se o setor é intensivo em mão de obra ou em } \\
\text { capital. }\end{array}$ \\
\hline $\begin{array}{l}\text { Índice de } \\
\text { Agregação de } \\
\text { Valor (IAV) }\end{array}$ & VTI / VBPI & $\begin{array}{l}\text { - Relação entre o Valor da Transformação Industrial (VTI) e o } \\
\text { Valor Bruto da Produção Industrial (VBPI) } \\
\text { - Mede o grau de internalização industrial ou de conteúdo } \\
\text { industrial - o quanto o setor maximiza seu fator de produção } \\
\text { com dada quantidade de recursos. }\end{array}$ \\
\hline $\begin{array}{l}\text { Participação do } \\
\text { emprego }\end{array}$ & $\begin{array}{l}\text { Empregados do } \\
\quad \text { setor / } \\
\text { Empregados na } \\
\text { Indústria de } \\
\text { Transformação }\end{array}$ & $\begin{array}{l}\text { - Mede a capacidade do setor de absorção de mão de obra - } \\
\text { quanto maior é o número de empregados do setor, mais } \\
\text { influência no mercado de trabalho ele terá. }\end{array}$ \\
\hline $\begin{array}{l}\text { Encadeamento } \\
\text { Setorial }\end{array}$ & $\begin{array}{l}\text { Custo de } \\
\text { Operações } \\
\text { Industriais - } \\
\text { Massa salarial }\end{array}$ & $\begin{array}{l}\text { - Mede a capacidade de encadeamento do setor por meio do } \\
\text { valor total em reais de insumos comprados de outros setores } \\
\text { durante o processo produtivo. }\end{array}$ \\
\hline $\begin{array}{l}\text { Taxa de } \\
\text { Crescimento do } \\
\text { Valor de } \\
\text { Transformação } \\
\text { Industrial }\end{array}$ & $\begin{array}{l}\text { (VTI_Presente } \\
\text { - VTI_Passado) } \\
\text { / VTI_Passado }\end{array}$ & - Reflete a dinâmica da atividade industrial. \\
\hline ICMS & $\begin{array}{l}\text { Valores } \\
\text { absolutos da } \\
\text { arrecadação de } \\
\text { ICMS }\end{array}$ & $\begin{array}{l}\text { - Permite identificar dois fatores chaves para a } \\
\text { competitividade: 1) quanto mais imposto é recolhido, maior é } \\
\text { a produção e agregação de valor do setor e 2) quanto maior é } \\
\text { o montante, maior será a receita e a capacidade de } \\
\text { investimento do poder público. }\end{array}$ \\
\hline Empresas & $\begin{array}{c}\mathrm{N}^{\mathrm{o}} \text { de empresas } \\
\text { do setor }\end{array}$ & - Reflete o tamanho do setor no estado. \\
\hline
\end{tabular}

Fonte: Elaboração própria, GPI.

Após a construção do Índice de Desempenho dos setores mineiros, foi realizada a Análise das Componentes Principais (ACP), uma técnica que transforma um conjunto de variáveis originais correlacionadas entre si em um novo conjunto de variáveis não correlacionadas (ortogonais), denominadas componentes principais.

Os indicadores foram calculados para 100 setores da economia de Minas Gerais e serviram como um instrumento para seleção de setores com mais dinâmica (componente 2), estabelecido como primeiro critério de seleção. Depois disso, esses setores foram ranqueados segundo o critério de capacidade de sobrevivência, denominados setores tradicionais (componente 1). Ao final dessa etapa, foi possível delimitar total de 21 
setores considerados 'setores dinamizadores' devido ao seu potencial para dinamizar a economia regional e estadual. E após a identificação do grupo de setores, foram desenvolvidas pesquisas qualitativas e quantitativas que estavam apoiadas em aplicação de questionários estruturados para 350 empresas de tais setores dinamizadores presentes nas 12 regionais de atuação do sistema FIEMG.

Figura 3 - Total de empresas entrevistadas, por regional FIEMG - PCIR

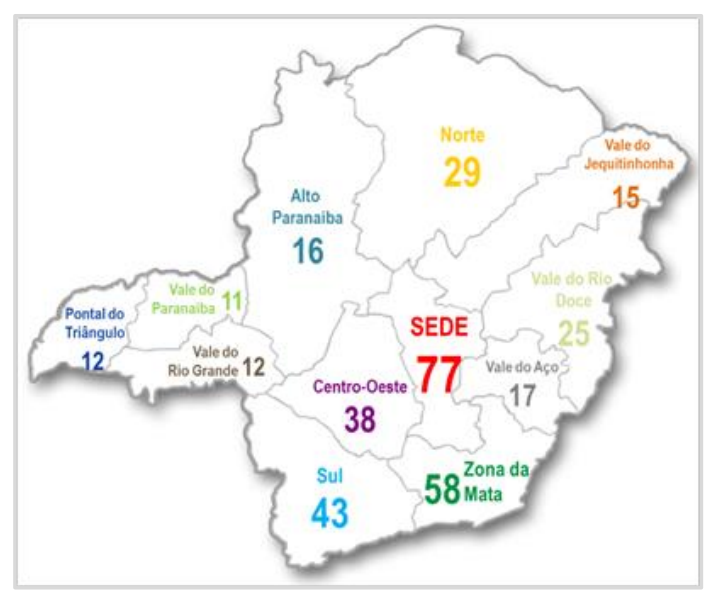

Fonte: Elaboração própria, GPI.

O questionário foi organizado em quatro áreas temáticas, com a finalidade de captar os principais pontos críticos de cada setor, sob o ponto de vista empresarial, e posteriormente organizá-los em Plano de Ação Setorial. Após essa atividade foi necessário realizar uma análise mais detalhada de dados quantitativos e qualitativos, considerando alguns setores com atuação transversal e que têm potencial dinamizador apenas em nível regional (não estadual) e que são denominados 'setores especiais'. A figura a seguir apresenta os 21 setores dinamizadores e os 5 especiais que foram contemplados pelo PCIR em todas as regionais de Minas Gerais.

Figura 4 - Setores dinamizadores e especiais identificados, por regional FIEMG - PCIR

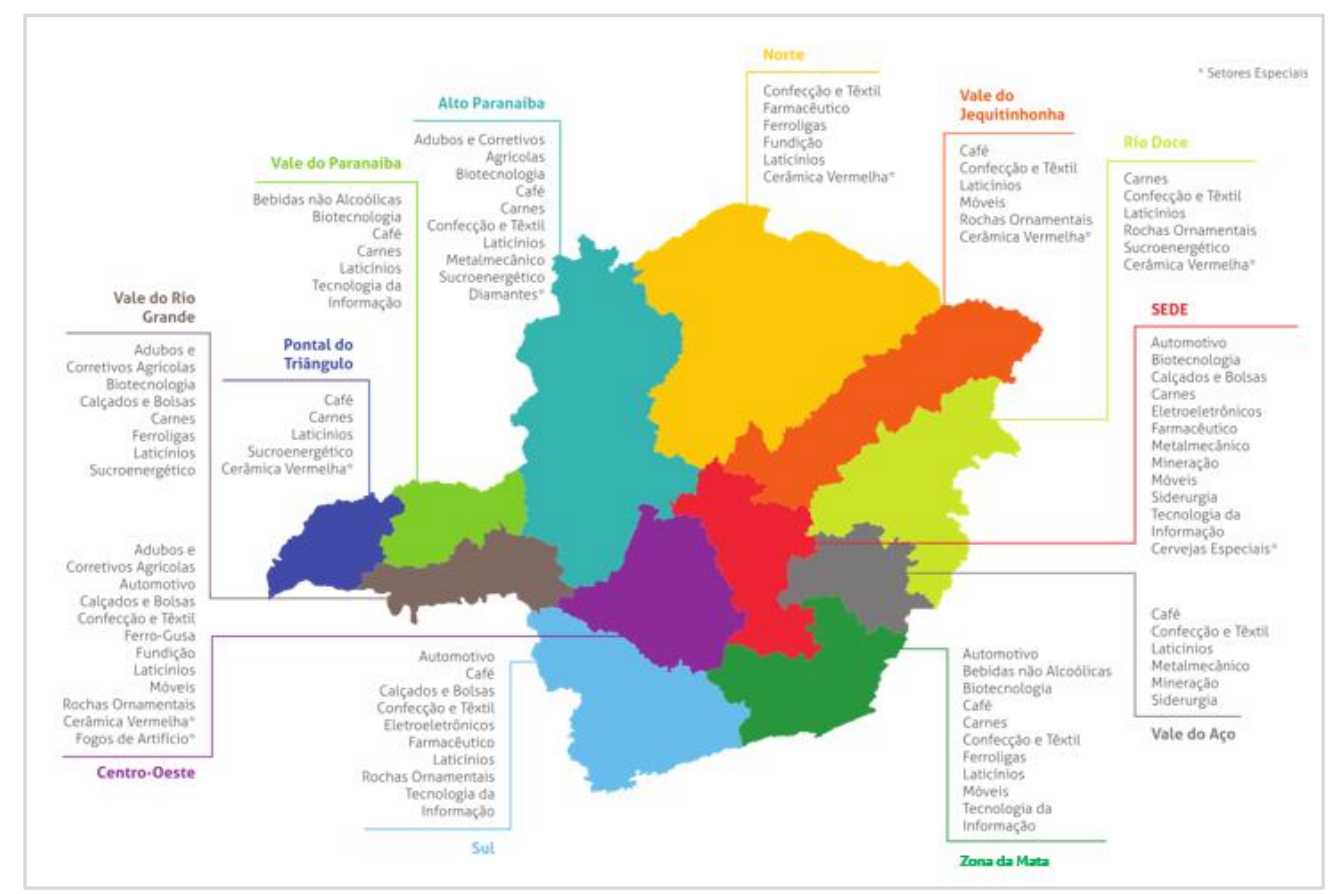

Fonte: Elaboração própria, GPI 
A $3^{\text {a }}$ etapa do Planejamento PCIR, realizada no período de março a dezembro/2015, contemplou duas atividades. a) Elaboração de Estratégia Setorial Regional e Proposição de ações de curto, médio e longo prazo para cada um dos 21 setores participantes do PCIR. b) Realização de 21 Encontros Setoriais, organizados em dois tipos de dinâmicas (reuniões técnicas e agendas propositivas) que reuniram grupos fechados de atores tais como especialista, formuladores e geradores de políticas, sindicatos patronais, empresas, universidades e centros de pesquisa/tecnologia e entidades de apoio, com o objetivo de debater a situação atual de cada setor e validar a $1^{\text {a }}$ versão da Matriz Propositiva Setorial.

Para a elaboração da Matriz Propositiva de Ações Setorial, foram utilizadas duas tipologias para classificação das ações: a) Tempo de duração previsto para cada ação que é classificado em: Curto prazo, para ações de até 1 ano de duração; Médio Prazo, para ações com duração entre 1 e 3 anos; e Longo prazo, para as ações com duração acima de 3 anos. Além disso, foi necessário categorizar as ações previstas em cada uma das 4 áreas temáticas (já contempladas no questionário), o que é apresentado no quadro a seguir.

Quadro 2 - Temas do Plano de Ações contemplados em cada Matriz Propositiva

\begin{tabular}{|c|c|}
\hline Temas & Principais Tipos de ações \\
\hline $\begin{array}{l}\text { Mão de Obra e } \\
\text { Recursos } \\
\text { Humanos }\end{array}$ & $\begin{array}{l}\text { - Ações de Capacitação em } 3 \text { níveis hierárquicos (Gerencial, Tático e } \\
\text { Operacional); } \\
\text { - Adequação da oferta de mão de obra com a demanda; e } \\
\text { - Boas práticas de Gestão de Recursos Humanos de forma a diminuir a } \\
\text { rotatividade de funcionários; }\end{array}$ \\
\hline $\begin{array}{l}\text { Tecnologia, } \\
\text { Inovação e } \\
\text { Modernização }\end{array}$ & $\begin{array}{l}\text { - Ações de apoio à modernização de parques industriais; } \\
\text { - Melhoria de processos de gestão da produção; } \\
\text { - Aprimoramento de gestão de qualidade; } \\
\text { - Apoio para difusão de conhecimento sobre recursos financeiros disponíveis } \\
\text { (financiamentos) para investimentos em tecnologia; } \\
\text { - Mapeamento da demanda por inovação tecnológica no mercado, relacionando- } \\
\text { a a pesquisas em andamento nas instituições. }\end{array}$ \\
\hline $\begin{array}{l}\text { Mercado e } \\
\text { Produto }\end{array}$ & $\begin{array}{l}\text { - Ações de desenvolvimento da cadeia fornecedora e de distribuição; } \\
\text { - Marketing empresarial e institucional; } \\
\text { - Plano de comunicação; } \\
\text { - Expansão da atuação mercadológica e promoção da imagem dos setores. }\end{array}$ \\
\hline $\begin{array}{l}\text { Exigências } \\
\text { Regulatórias e } \\
\text { Sustentabilidade }\end{array}$ & $\begin{array}{l}\text { - Ações para aproximar empresas e governança a órgãos nacionais que exercem } \\
\text { influência sobre o setor; } \\
\text { - Articulação para revisão de normas; } \\
\text { - Preparação de empresas para se adequarem às exigências regulatórias } \\
\text { ambientais, de ergonomia e normas regulamentadoras (NRs) do Ministério do } \\
\text { Trabalho e Emprego; } \\
\text { - Melhoria de canais de destinação dos resíduos industriais; } \\
\text { - Apoio para melhor aproveitamento de recursos energéticos; } \\
\text { - Criação de plano de reutilização da água nas indústrias. }\end{array}$ \\
\hline
\end{tabular}

Fonte: Elaboração própria, GPI.

A $4^{\text {a }}$ e última etapa do processo de Planejamento do Programa de Competitividade Industrial contemplou as seguintes atividades: a) Consolidação de conteúdos gerados nas etapas anteriores; b) Elaboração dos Planos de Desenvolvimento Industrial para as 12 Regionais do estado; c) Análise, detalhamento e precificação das ações propostas para cada setor; e d) Identificação de potenciais parceiros para cada tema abordado. 
A finalidade principal desta etapa foi reforçar a importância do olhar setorial no estado, levando em consideração suas peculiaridades e demandas. Além disso, pretendiase estruturar o modelo de governança do programa a fim de viabilizar apoio público e privado e promover o seu alinhamento com planejamentos das demais entidades envolvidas. Nesse sentido, todas as iniciativas e principais gargalos setoriais apresentados na Matriz Propositiva foram alinhados e validados com bases empresariais, sindicais e regionais. Em dezembro de 2015, após a $4^{\mathrm{a}}$ etapa do processo de Planejamento, o Programa de Competitividade Industrial Regional (PCIR) foi lançado oficialmente por meio de um portal e da entrega dos Planos Setoriais e regionais para representantes de todas as regionais de atuação do sistema FIEMG.

O processo de Execução do PCIR contempla ações de curto, médio e longo prazo que começaram a ser executadas no início de 2016, utilizando capacidades técnicas do Sistema FIEMG e de outros parceiros institucionais, além de contratações de consultorias externas. Desde o início do processo de execução, as governanças de cada regional têm contribuído com a seleção dos primeiros setores a serem beneficiados e das ações prioritárias para execução. E após tal seleção, as equipes responsáveis pela execução têm optado por atendimentos coletivos (várias empresas de mesmo setor ou de setores diferentes), de forma a obter preços menores com fornecedores e assim diluir custos de cada ação.

Para avaliar as ações executadas em todos 26 setores dinamizadores do estado, o Programa de Competitividade Industrial Regional utiliza, principalmente 8 indicadores de resultados previamente alinhados a partir de Acordo de Resultados do sistema FIEMG: a) Total de sindicatos atendidos; b) Total de indústrias atendidas; c) Total de setores atendidos; d) Projetos e ações Regionais e Setoriais; e) Inserções espontâneas na mídia de projetos e ações; f) Resultado Operacional; g) Índice de satisfação das ações regionais e ações setoriais; h)Número de parceiros.

A próxima seção apresenta os principais resultados obtidos na execução de ações do PCIR no período de 2016 a 2017, destacando os fatores determinantes para o desempenho do projeto.

\section{RESULTADOS E DISCUSSÕES}

\subsection{A execução do Programa de Competitividade Industrial Regional no período de 2016-2018}

Desde o seu lançamento em dezembro de 2015, o Programa de Competitividade Industrial Regional (PCIR) tem representado um esforço direcionador de agentes privados e públicos em prol do desenvolvimento regional e setorial.

$\mathrm{O}$ ano de 2016 foi marcado como uma fase de estabelecimento, reconhecimento e identificação das governanças regionais e de execução das primeiras ações do projeto. Neste ano foram realizadas 85 ações, sendo 71 ações setoriais e 14 ações multisetoriais, o que superou todas as metas estabelecidas previamente. Entre as ações executadas em 2016 destacam-se encontros de negócio, workshops, missões internacionais, estudos de prospecção de mercado, planos de gestão de pessoas, projetos de posicionamento de marcas, consultorias de gestão financeira, lean manufacturing e serviços de aperfeiçoamento em metrologia.

No ano de 2017 o programa também superou as metas de execução estabelecidas para as 12 regionais e os 26 setores, por meio da realização de 232 ações, sendo que 94 delas eram multisetoriais. Além disso, até dezembro de 2017 foram beneficiadas mais de 15.000 pessoas participantes de ações como consultorias, capacitações, dinâmicas workshops e encontros técnicos. 
A tabela a seguir apresenta o total de ações realizadas em 2016 e 2017, considerando o público-alvo (sindicatos, indústria e setores) e temas de atuação PCIR.

Tabela 1 - Total de ações realizadas em 2016 e 2017

\begin{tabular}{|c|c|c|c|}
\hline Atendimentos PCIR & $\begin{array}{c}\text { Ações } \\
\text { executadas em } \\
2016 \\
\end{array}$ & $\begin{array}{c}\text { Ações } \\
\text { executadas em } \\
2017 \\
\end{array}$ & $\begin{array}{c}\text { Taxa de crescimento } \\
2017 / 2016 \\
(\%)\end{array}$ \\
\hline \multicolumn{4}{|l|}{ Por Público-alvo $^{1}$} \\
\hline 1.Sindicatos & 54 & 58 & 7 \\
\hline 2. Indústrias & 990 & 2415 & 144 \\
\hline 3. Setores & 19 & 26 & 37 \\
\hline \multicolumn{4}{|l|}{ Por área temática } \\
\hline 1. Mão de obra e Recursos Humanos & 36 & 124 & 244 \\
\hline 2. Tecnologia e Inovação & 8 & 43 & 438 \\
\hline 3. Mercado e Produto & 30 & 34 & 13 \\
\hline 4. Exigências Regulatórias e & 11 & 31 & 182 \\
\hline $\begin{array}{l}\text { Sustentabilidade } \\
\text { Total (por tema PCIR) }\end{array}$ & 85 & 232 & 173 \\
\hline
\end{tabular}

Após dois anos de execução, foi realizado um total de 317 ações em 3.444 indústrias dos 26 setores contemplados pelo programa. Como pode ser visto na figura a seguir, o PCIR também obteve bons índices de satisfação empresarial e gerou uma grande quantidade de repercussões online, que são relevantes para fomentar a visão de longo prazo nos setores e regiões atendidos.

Figura 5 - Status geral das ações PCIR até 31/12/2017

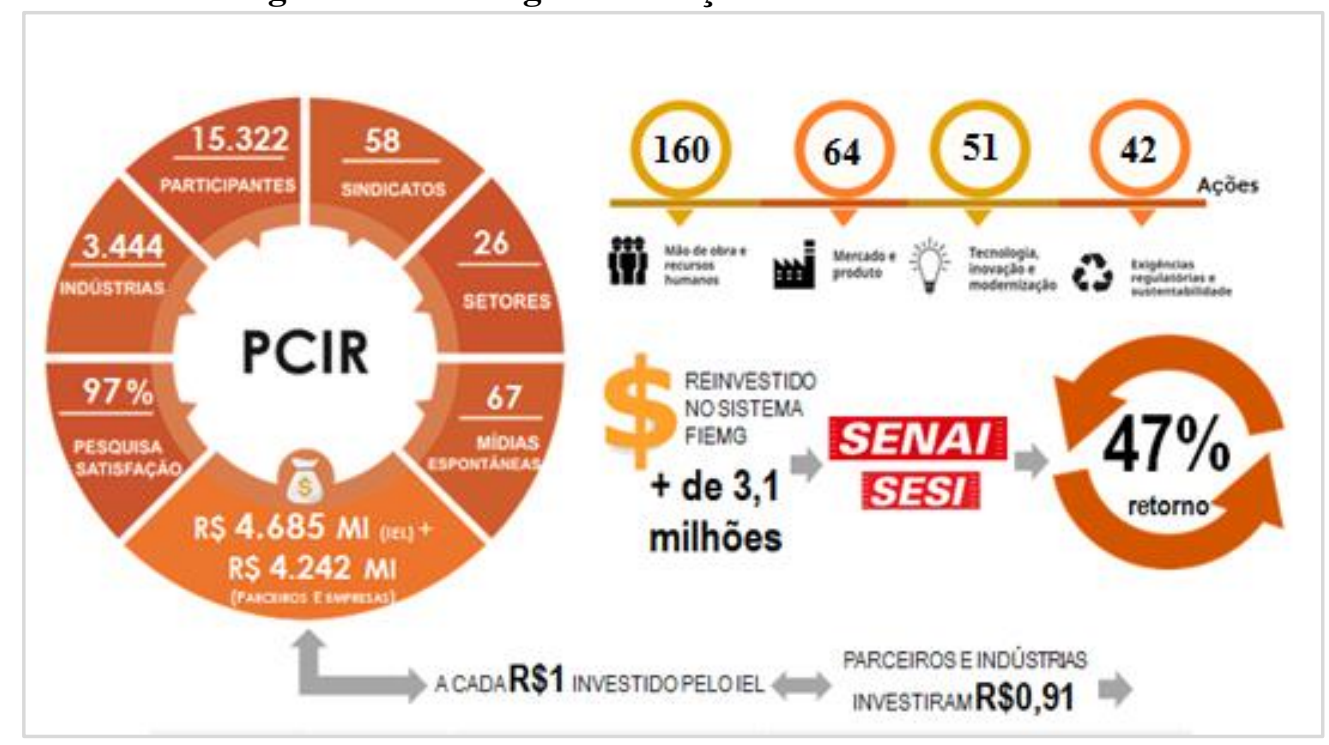

Fonte: Elaboração própria, GPI.

No período 2016-2017 o PCIR conseguiu reinvestir bons montantes (cerca de $35 \%$ ) em entidades do Sistema FIEMG (como SENAI e SESI), constituindo assim um "pool de talentos" com capacidade técnica interna para atender a indústria. Além disso, ao observar os valores da receita do programa, por exemplo, verifica-se que a cada $R \$ 1$ investido pelo IEL, os parceiros e indústrias investiram $\mathrm{R} \$ 0,91$.

Vale notar que embora os setores industriais de Minas Gerais apresentem diferentes condições entre si, a maioria das empresas tende a apresentar em comum, muitos desafios nas áreas temáticas "Mão de Obra e Recursos Humanos"; e "Exigências Regulatórias e Sustentabilidade", que demandam a execução de ações com horizonte de 
tempo de curto e médio prazo. Entretanto, muitas empresas também tendem a apresentar diferentes desafios nas áreas temáticas "Mercado e Produto" e "Tecnologia, Inovação e Modernização", que estão diretamente relacionados à característica técnica e/ou comercial de cada empresa e demandam ações com tempo de execução e de maturidade no longo prazo.

A instabilidade econômica nacional inibe investimentos em ações que geralmente apresentam custos mais elevados e maiores riscos de insucesso e por esse motivo, tem influenciado a demanda das empresas naquele último grupo de ações.

Considerando esse cenário, no período de 2016 a 2017, o Programa de Competitividade Industrial Regional concentrou mais esforços em ações de menor complexidade e de execução no curto prazo, para posteriormente incentivar e apoiar ações que demandam mais investimentos e prazo para maturação.

Dessa forma, foi possível preparar ou atualizar várias empresas em aspectos como formação de mão de obra, acesso a mercado e exigências regulatórias, por exemplo. A área temática "Mão de Obra e Recursos Humanos" apresentou maior número de ações executadas em 2017, com total de 160 ações. Já as áreas de "Exigências Regulatórias e Sustentabilidade", "Mercado e Produto" e "Tecnologia, Inovação e Modernização" apresentaram, respectivamente, 51, 42 e 64 ações executadas no período de janeiro de 2016 a dezembro de 2017.

Nos primeiros quatro meses de 2018, o programa apresentou total de 23 ações em execução, 7 ações concluídas e tem a meta de realizar cerca de 130 ações nas 12 regionais do estado. Entretanto, o programa tem enfrentado outros dois desafios. Em primeiro lugar, a instabilidade do ambiente econômico nacional, caracterizado pela intermitência das políticas e de recursos público, refletem em ausência de visão de longo prazo da indústria e podem repercutir na execução de ações do programa. Em segundo lugar, o Brasil e o estado de Minas Gerias também lidam com mudanças em sua dinâmica industrial atribuídas, especialmente, à difusão da tecnologia da informação e da comunicação e à emergência de tecnologias habilitadoras da Indústria 4.0 como $I o T^{7}$. De maneira geral, essas tecnologias têm refletido em alterações na estrutura produtiva, configurando assim um novo cenário para a sobrevivência e desempenho de empresas de todos os portes.

Diante desse cenário, o Programa de Competitividade Industrial mantém seu objetivo de contribuir para a competitividade industrial em Minas Gerais e estabeleceu, para os próximos cinco anos, a estratégia de avançar também na execução de ações das áreas temáticas "Tecnologia, Inovação e Modernização" e "Mercado e Produto", considerando as características e desafios identificados para cada setor priorizado pelo programa.

Entre os mecanismos utilizados para viabilizar a transição entre áreas temáticas, destaca-se a maior articulação com governança e a sensibilização com empresas que já participaram de ações voltadas à Melhoria de Processos ou com aquelas empresas que têm estrutura produtiva, condições financeiras e maturidade empresarial para realizar investimentos em ações com perfil mais estruturante ${ }^{8}$. As ações de Melhorias do Processo produtivo como Consultorias em Lean Manufacturing ${ }^{9}$, por exemplo, foram bastante requisitadas pelas empresas participantes do PCIR. Conforme ocorrem o desenvolvimento de tais ações e o amadurecimento das governanças nas diversas regiões, identifica-se entre algumas dessas empresas o potencial para realização de outras ações visando modernização processos com a incorporação de IoT e tecnologia de informação, por exemplo.

\footnotetext{
${ }^{7}$ Sigla em inglês que significa internet das coisas e que se refere a interconectividade entre máquinas e equipamentos, uma das tecnologias habilitadoras da indústria 4.0 (CNI, 2017).

${ }^{8}$ A próxima seção retomará essa discussão utilizando como exemplo o setor sucroenergético do Triângulo Mineiro.

${ }^{9}$ Ação refere-se à consultorias em lean manufacturing, ou Manufatura Enxuta, que é consultoria de baixa complexidade e de extrema importância, que propicia a organização e a melhoria dos processos produtivos de uma indústria. As ações de Lean foram muito presentes no início do PCIR.
} 
A execução do programa também promoverá maior alinhamento aos Focos Estratégicos do Sistema FIEMG "Inovação e Tecnologia"; e "Desenvolvimento e Defesa da Indústria". No primeiro Foco Estratégico, as ações do PCIR estão alinhadas às três diretrizes do sistema:

1. Gestão estratégica e Inteligência em propriedade intelectual: valorização do conhecimento como vantagem competitiva de um negócio, remetendo à necessidade de se desenvolver estratégicas de proteção intelectual e de utilização desses ativos.

2. Gestão da Inovação: trabalho conjunto visando contribuir para que as empresas desenvolvam capacidade de gerar, continuamente, inovação.

3. Estímulo à Cultura e Talentos para Inovação: promoção de projetos de PD\&I nas empresas e institutos privados, qualificando os profissionais para a execução de projetos de inovação no ambiente empresarial e estimulando o desenvolvimento da cultura da inovação nas empresas.

Já no foco estratégico "Desenvolvimento e Defesa da Indústria", o programa continua contribuindo para o estabelecimento e fortalecimento das governanças locais, criando parcerias de longo prazo com objetivos claros através do estabelecimento de mecanismos formais e que propiciem contribuições técnicas e tecnológicas de alta relevância para o setor.

O programa também tem incorporado e melhorado dois processos que abrem novas possibilidades para a sua execução a partir de 2018: a) Captação de Recursos, processo que monitora e prospecta parcerias institucionais e recursos financiáveis convergentes com os projetos executados pela gerência; e b) Comunicação, processo que auxilia todo o trabalho de prospecção, sensibilização, registro, elaboração de documentos técnicos e acadêmicos e repercussão na mídia após as ações.

Desse modo, a perspectiva para atuação do programa para os próximos anos é de manutenção do quantitativo de ações e atendimentos, incluindo aquelas mais estruturantes e que demandam mais investimentos; continuidade do trabalho realizado junto aos 26 setores dinamizadores; e prospecção e maior alinhamento visando a entrada de novos parceiros institucionais que irão agregar ao atendimento e execução de ações.

A próxima seção destaca a execução do PCIR no setor sucroenergético da região do Triângulo Mineiro, narrando brevemente a transição entre ações voltadas à Mão de obra e Exigências Regulatórias e aquelas ações direcionadas a promover a implantação de tecnologias habilitadoras da Indústria 4.0 na região, o justifica a metáfora utilizada no artigo - "das consultorias de Lean aos desafios da Indústria 4.0" - ilustrando a transição entre áreas temáticas e a preocupação de intensificar as relações institucionais e os desenvolvimentos técnico-tecnológicos em Minas Gerais.

\subsection{Considerações sobre a execução do PCIR no setor sucroenergético do Triângulo Mineiro}

O Programa de Competitividade Industrial Regional está no $3^{\circ}$ ano de execução (2016-2018) e durante todo esse período, tem enfrentado alguns desafios de ordem macroeconômica e política que têm repercutido nas decisões das empresas de investirem e participarem de programas visando fortalecimento e competitividade industrial. $\mathrm{O}$ surgimento do conceito de Indústria 4.0 também é um aspecto que vem transformando a produção industrial com novos processos, produtos e modelos de negócios impensáveis há poucos anos. Esse fenômeno transformou os modelos convencionais de produção, que apresentam cada vez riscos inerentes a sua ineficácia quando comparado às novas estratégias industriais. Entretanto, para diversos segmentos industriais, a transição dos modelos convencionais de produção para modelos mais intensivos em tecnologia requer 
o entendimento e a adoção de novos métodos e ferramentas que permitam traçar uma trilha de evolução ancorada aos novos conceitos de Indústria 4.0.

O Programa de Competitividade Industrial Regional (PCIR) se insere como ferramenta prática na tentativa de apoiar a indústria mineira nessa trilha, adotando dimensões técnicas para contribuir com a evolução do desenvolvimento industrial de Minas Gerais. Como dimensões técnicas, o PCIR considera como necessária a articulação institucional, e a atuação nas áreas temáticas que priorizam formação dos recursos humanos, adequação às exigências regulatórias, prospecção de novos mercados e desenvolvimento tecnológico de novos produtos e processos.

O setor sucroenergético é um dos setores considerados dinamizadores da economia de Minas Gerais, contemplando as atividades agrícolas e industriais de produção de açúcar, bioetanol e bioeletricidade. Além disso, muitas usinas também produzem energia elétrica com o bagaço e palha da cana (energia de biomassa), sendo autossuficientes e até vendendo o excedente da energia produzida para o Sistema Integrado Nacional (SIN). Um dos principais resultados gerados pelo setor sucroenergético é a geração de energias limpas e renováveis: etanol e bioeletricidade ${ }^{10}$.

Em 2016, o Brasil se posicionava como o maior produtor e exportador mundial de açúcar (cerca de $23 \%$ produção global e $49 \%$ da exportação mundial) e o segundo maior produtor de etanol. Na safra de 2016/17, o setor apresentava faturamento de R\$ 100 bilhões de reais, se posicionando em $3^{\circ}$ lugar na pauta de exportação do agronegócio. Além disso, em todo o país, o setor contava com mais de 350 unidades produtivas que geravam cerca de 794 mil empregos formais, de acordo com os dados do Ministério do Trabalho de 2016.

Em Minas Gerais, até a safra de 2017/18, o setor apresentava 33 usinas em funcionamento, das quais 21 produziam açúcar e etanol, 10 somente etanol e 3 somente açúcar. A atividade do setor sucroenergético gerava, em Minas Gerais, cerca de 55 mil empregos diretos e apresentava concentração de suas unidades de produção na região do Triângulo Mineiro, na qual se encontram 21 usinas.

A produção sucroenergética de Minas Gerais está concentrada na região do Triângulo Mineiro, situada no oeste do Estado, e abrange três regionais de atuação do Sistema FIEMG: 1) Regional Vale do Paranaíba, que contempla 14 municípios e possui Uberlândia como cidade polo; 2) Regional Vale do Rio Grande, com 20 municípios sendo Uberaba a cidade polo; e 3) Regional Pontal do Triângulo, que contempla 15 municípios e possui Ituiutaba como cidade polo ${ }^{11}$.

Diante de seu dinamismo na geração de emprego e renda e da geração de energias limpas e renováveis, o setor sucroenergético foi considerado dinamizador no âmbito do Programa de Competitividade Industrial Regional (PCIR) do Sistema FIEMG, e atualmente é exemplo da atuação do programa.

A partir do início de 2016, após o lançamento público do PCIR e do seu site ${ }^{12}$, iniciou-se a fase de execução do programa no setor sucroenergético de Minas Gerais. $\mathrm{O}$ primeiro passo para a execução das ações propostas foi a constituição e fortalecimento da governança setorial, formada por membros do Sistema FIEMG, por meio do Instituto Euvaldo Lodi/ Minas Gerais (IEL/MG) e de suas Regionais FIEMG presentes no Triângulo Mineiro, pelo Serviço Brasileiro de Apoio às Micro e Pequenas Empresas (SEBRAE) e pela Associação das Indústrias Sucroenergética do estado de Minas Gerais (SIAMIG).

\footnotetext{
${ }^{10}$ A expansão do consumo de etanol pelos carros flex, por exemplo, acarretou em diminuição da emissão de gases de efeito estufa, reforçando sua importância na geração de energia limpa.

${ }^{11}$ Essa região se destaca pelo potencial do agronegócio e pela presença de grandes empresas voltadas aos setores de processamento de alimentos, de açúcar e álcool, e de adubos e fertilizantes

12 Para mais informações sobre o site do PCIR, sugere-se consultar:

https://www7.fiemg.com.br/iel/produto/programa-de-competitividade-industrial-regional-pcir-
} 
Posteriormente foram instituídos encontros, geralmente com a periodicidade mensal, para discussão da priorização das ações para o setor, além da busca por novas parcerias estratégicas que viabilizassem a execução das proposições desenhadas no plano setorial. $\mathrm{O}$ quadro a seguir apresenta as áreas temáticas priorizada pela governança setorial e alguns exemplos de ações executadas no período 2016-2018.

\section{Quadro 3 - Exemplos de ações executadas no setor sucroenergético do Triângulo Mineiro} (2016-18)

\begin{tabular}{|c|c|c|}
\hline $\begin{array}{l}\text { Área temática } \\
\text { priorizada }\end{array}$ & Ação realizada & Principais resultados \\
\hline $\begin{array}{c}\text { Mão de Obra e } \\
\text { Recursos Humanos }\end{array}$ & $\begin{array}{l}\text { Capacitação técnica; } \\
\text { Capacitação gerencial }\end{array}$ & $\begin{array}{l}\text { Cerca de } 1.200 \text { funcionários capacitados em: } \\
\text { destilaria, tratamento e fermentação do caldo, } \\
\text { habilidades gerenciais, conhecimentos em e-social, } \\
\text { liderança assertiva, entre outros no período de } \\
2016-17 \text {. }\end{array}$ \\
\hline Mercado e Produto & $\begin{array}{l}\text { Missão para prospecção } \\
\text { de novos fornecedores } \\
\text { mineiros para as usinas } \\
\text { do Triângulo Mineiro }\end{array}$ & $\begin{array}{l}\text { Produção e fornecimento de faca de colheitadeira } \\
\text { (faquinha), usada no corte da cana-de-açúcar, de } \\
\text { acordo com necessidades do setor sucroenergético. }\end{array}$ \\
\hline \multirow{2}{*}{$\begin{array}{c}\text { Tecnologia, Inovação } \\
\text { e Modernização }\end{array}$} & $\begin{array}{c}\text { Consultoria em } \\
\text { manufatura enxuta }\end{array}$ & $\begin{array}{l}\text { Melhoria de processo produtivo, com redução de } \\
\text { custos com estoque e aumento de produtividade. }\end{array}$ \\
\hline & Implementos rodoviários & $\begin{array}{l}\text { Elaboração de estudo de viabilidade e posterior } \\
\text { protótipo para ser testado em usinas do Triângulo } \\
\text { Mineiro. }\end{array}$ \\
\hline
\end{tabular}

Fonte: Elaboração própria, GPI.

No $2^{\circ}$ semestre de 2016, essa governança setorial definiu 'Mão de Obra e Recursos Humanos' como primeira área temática para execução de ações. Caracterizado como intensivo em mão de obra, o setor sucroenergético emprega na região do Triângulo Mineiro aproximadamente 102 mil funcionários (diretos e indireto). E inúmeras usinas possuem sua unidade fabril em zonas rurais de difícil acesso, o que é um obstáculo para o setor viabilizar capacitações para os seus empregados.

Mediante o apoio do SIAMIG, foram realizadas consultas junto aos departamentos de recursos humanos de 34 usinas associadas de forma a detalhar mais as principais necessidades de cursos e treinamentos "in loco" para funcionários das unidades produtivas. Posteriormente, o PCIR viabilizou, via parcerias firmadas com o Serviço Nacional de Aprendizagem Industrial de Minas Gerais (SENAI-MG) e o Centro Industrial e Empresarial de Minas Gerais (CIEMG), um programa de qualificação e aprendizagem da mão de obra das usinas, dividido em 2 temáticas: a) Capacitações técnicas: realizadas por meio de dinâmicas práticas e/ou teóricas e direcionadas para a atividade-fim; e Capacitações de gestão: realizadas por meio de encontros coletivos e consultorias individuais, voltados aos processos administrativos e de liderança das usinas.

A segunda área temática do PCIR priorizada pela governança setorial para execução de ações foi a área "Mercado e Produto", na tentativa de prospectar novos fornecedores mineiros para as usinas do Triângulo Mineiro, cuja maior parte dos insumos industriais é proveniente do estado de São Paulo.

Para prospectar novas possibilidades de fornecimento de componentes para os equipamentos utilizados na coleta e corte da cana de açúcar, foi realizada uma missão empresarial que contemplou visitas técnicas nas unidades de produção e reuniões entre empresários do setor sucroenergético e do arranjo produtivo local (APL) de metalmecânico do Vale Aço. A missão foi acompanhada por técnicos do Sistema FIEMG e permitiu a identificação de potencial demanda por produção de uma peça denominada faca de colheitadeira - "a faquinha" - que é usada no corte da cana-de-açúcar e possui 
uma vida útil muito curta, havendo a necessidade de substituição mais de uma vez por dia.

Durante a missão, foram coletadas amostras da peça e posteriormente, por meio de mais uma parceria firmada via PCIR, o SENAI MG analisou a resistência do material utilizado para produção das facas e divulgou as informações para a assessoria técnica de empresas do Vale do Aço, para a fabricação de peças mais resistentes. Como resultado desta ação, algumas empresas do setor metalmecânico manifestaram interesse na produção e fornecimento da peça para as usinas, o que pode gerar um volume de negócios estimado em cerca de R \$ 8 milhões por safra no mercado de Minas Gerais

Após a boa abertura do setor às induções técnicas e primeiras ações do programa, a governança setorial definiu 'Tecnologia, Inovação e Modernização 'como a terceira área temática para atuação entre as empresas do Triângulo Mineiro.

As usinas produtoras de açúcar, álcool e energia possuem duas estruturas dentro da mesma unidade fabril: área agrícola e industrial. A área agrícola representa o maior custo de produção (cerca de $80 \%$ ) dentro da estrutura de cada usina e tem forte dependência de pesquisas aplicadas para melhoria da produtividade de processo. Já a área industrial apresenta fortes demandas de processos mais enxutos e ágeis, com o intuito de aumentar a produtividade do setor.

Mediante a importância que o processo produtivo desempenha para as duas estruturas da usina, foi priorizada a execução de ações coletivas voltadas à implementação do conceito da manufatura enxuta (lean manufacturing) ${ }^{13}$ junto aos gerentes industriais de 02 usinas no Alto Paranaíba. Por meio da aplicação de atividades tais como análise de tempos de troca mínimos, implementação do planejamento da produção puxada, eliminação de defeitos e implantação de one piece flow (lote unitário), as usinas contempladas por essa ação obtiveram ganhos como: redução de $30 \%$ no custo com estoque e aumento de $14 \%$ da produtividade.

Ainda dentro dessa área temática, outro aspecto que influencia o desempenho das empresas é que, de maneira geral, elas apresentam altos custos de logística atrelados ao transporte da cana (representa cerca de $40 \%$ do custo do produto final). Além disso, a ausência de modelos de veículos desenvolvidos para a indústria canavieira e a necessidade de atendimento ao Termo de Ajuste de Conduta (TAC) são dificuldades recorrente para o transporte da cana.

Nesse cenário, a governança setorial solicitou execução de ação que possibilitasse a aproximação entre fabricantes de implementos rodoviários ${ }^{14}$ e as usinas de Minas Gerais, de forma a viabilizar o desenvolvimento de um estudo de novo implemento rodoviário que deveria ser mais leve, mais resistente e adequado à legislação vigente, e que promovesse a redução dos custos de transporte do setor sucroenergético.

$\mathrm{O}$ estudo conduzido em parceria com centro de uma empresa de implementos rodoviários analisou a viabilidade técnica e financeira de um novo implemento que viabilizará a redução de custo no transporte da cana. A entrega final do estudo foi realizada para o SIAMIG (Associação das Usinas Sucroenergéticas do estado de Minas Gerais) que iniciou, junto aos produtores de implementos rodoviários mineiros, a elaboração de 3 protótipos a serem testados nas usinas do Triângulo Mineiro em 2019.

Instituindo como ponto de partida a estruturação da governança setorial e regional como instância de decisão dos projetos a serem realizados, e passando pelas áreas temáticas de formação de recursos humanos, adequação às exigências regulatórias, melhoria de processo produtivo, fortalecimento de mercado e desenvolvimento de novas

\footnotetext{
${ }^{13}$ Baseado no Sistema Toyota de Produção que prevê a diminuição dos desperdícios em todos os processos que não agregam valor ao produto que está sendo comercializado.

${ }^{14}$ De acordo com Goldenstein et al 2006 (p. 242), os implementos rodoviários são os "reboques, semi-reboques e carrocerias, ou seja, os componentes do caminhão responsáveis pela função específica do transporte de cargas".
} 
tecnologias, o PCIR buscar reunir parte dos elementos necessários à formação de um ambiente propício à inovação e ganhos de competitividade das empresas de Minas Gerais.

Desse modo, a partir das ações executadas para o setor sucroenergético, o Programa de Competitividade Industrial Regional confirma sua intenção de servir de ferramenta de apoio ao setor industrial mineiro na evolução das dimensões técnicas necessárias ao desenvolvimento de tecnologias habilitadoras da Indústria 4.0.

\section{CONCLUSÃO}

O Programa de Competitividade Industrial Regional discutido neste artigo é uma iniciativa inovadora e de execução complexa, que visa promover a competitividade de diferentes setores industriais, independentemente de suas empresas estarem localizadas geograficamente próximas ou não.

A constituição do programa está pautada em estudos e análises que consideram características, especificidades e desafios enfrentados por vários setores industriais, assim como a sua relevância para a economia regional e do estado de Minas Gerais. Nesse cenário, o programa considerou quatro aspectos - regional, setorial, institucional e temático - para planejar, executar e monitorar ações que contemplem características e desafios.

Desde o seu início, o programa já obteve vários resultados positivos, como elevado número de ações executadas em vários setores, grande número de empresas e participantes, aumento da capilaridade regional e setorial e fortalecimento da governança setorial e local.

Particularmente o estabelecimento, fortalecimento e a articulação do programa com a governança setorial das 12 regionais de atuação FIEMG foram fundamentais para o seu desenvolvimento e atualmente têm contribuído muito para a execução e os resultados obtidos pelo programa. Nesse sentido, a interação com a governança setorial tem sido um meio pra viabilizar a execução do programa, mas também é o foco de atuação do Instituto Euvaldo Lodi que tem entre seus objetivos, a atuação mais compartilhada e crescimento de iniciativas de desenvolvimento industriais menos polarizadas setorialmente e regionalmente. Além disso, o programa apresenta parcerias com entidades do sistema $\mathrm{S}$ e algumas instituições públicas e privadas (estadual e nacional).

Vale notar que o PCIR tem enfrentado alguns desafios como a instabilidade macroeconômica (nacional e estadual) e política e algumas mudanças na dinâmica industrial, a partir da difusão de tecnologias da informação e da emergência de tecnologias habilitadoras da Indústria 4.0, que têm refletido, de forma distinta na estrutura produtiva de empresas, configurando assim um novo cenário para a sua sobrevivência e desempenho.

No setor sucroenergético da região do Triângulo Mineiro, atualmente a governança tem contribuído tanto para a coordenação e a organização da participação de diversos atores no processo decisório, como para a execução de ações coletivas (para grupo de empresas do setor). Nesse sentido, a identificação de desafios e o trabalho setorial conjunto em ações de capacitação e exigências regulatórias, e posteriormente, em ações com perfil mais estruturante, têm sido uma boa estratégia para preparar e atualizar as empresas do setor diante das adversidades econômicas e técnicas-tecnológicas.

Diante desse cenário, o fortalecimento da governança, a prospecção de novas parcerias e fontes de recursos, assim como a estratégia de promover a transição entre áreas temáticas do programa, de acordo com alinhamentos e necessidades de cada setor, têm viabilizado a execução das ações, contribuindo assim para o papel do Instituto Euvaldo Lodi de apoiar as empresas de Minas Gerais no enfrentamento de dificuldades e em iniciativas voltadas à ganhos de competitividade industrial. 


\section{REFERÊNCIAS BIBLIOGRÁFICAS}

CONFEDERAÇÃO NACIONAL DAS INDÚSTRIAS (2017). Oportunidades para a indústria 4.0: aspectos da demanda e oferta no Brasil. Confederação Nacional da Indústria. Brasília: CNI, 2017. Disponível em: http://www.portaldaindustria.com.br/publicacoes/2018/2/oportunidades-para-industria40-aspectos-da-demanda-e-oferta-no-brasil/. Acesso em: 05/maio/2018.

CASSIOLATO, José Eduardo; LASTRES, Helena M. M; STALLIVIERI, Fábio (2008) Introdução: Políticas estaduais e mobilização de atores políticos em Arranjos Produtivos e Inovativos Locais. In: CASSIOLATO, José Eduardo; LASTRES, Helena M. M; STALLIVIERI, Fábio (org). Arranjos Produtivos Locais - uma alternativa para o desenvolvimento. Rio de Janeiro: E-papers, Volume 2, pp. 11-39, 2008.

CARDOSO, Univaldo Coelho; CARNEIRO, Vânia Lúcia Nogueira; RODRIGUES, Édna Rabêlo Quirino (2014). Arranjo Produtivo Local. In: Série Empreendimentos Coletivos. Brasília: Serviço Brasileiro de Apoio à Micro e Pequenas Empresas, 2014.

Disponível

em: http://www.bibliotecas.sebrae.com.br/chronus/ARQUIVOS_CHRONUS/bds/bds.nsf/b8 126fa768f69929a146f38122da570b/\$File/5197.pdf

CONEJERO, Marco Antônio; CÉSAR, Aldara da Silva (2017). A governança de Arranjos Produtivos Locais (APLs) para a gestão estratégica de indicações geográficas (IGS). Revista Ambiente e Sociedade. São Paulo, Volume XX, Número 01, pp. 279-300, Jan-mar/2017. Disponível em: http://www.scielo.br/pdf/asoc/v20n1/pt_1809-4422-asoc-20-01-00293.pdf

GOLDENSTEIN, Marcelo; ALVES, Marcelo de Figueiredo; AZEVEDO, Rodrigo Luiz Sias de. A indústria de implementos rodoviários e sua importância para o aumento da eficiência do transporte de cargas no Brasil. BNDES Setorial, Rio de Janeiro, n. 24, p. 241-260, 2006.2 Disponível em: https://web.bndes.gov.br/bib/jspui/handle/1408/2423

INSTITUTO EUVALDO LODI (2015). Programa de Apoio a Competitividade dos Arranjos Produtivos Locais de Minas Gerais. Relatório final. No prelo.

INSTITUTO EUVALDO LODI (2014). Programa de Competitividade Industrial Regional (PCIR). 2014. Disponível em: http://pcir.fiemg.com.br/sobre

JACOMETI, Márcio; CASTRO, Marcos; GONÇALVES, Sandro Aparecido; COSTA, Mayla Cristina (2017). Análise de efetividade das políticas públicas de Arranjo Produtivo Loca para o desenvolvimento local a partir da teoria institucional. Revista de Administração Pública (online), Rio de Janeiro, Volume 50, Número 3, Maio-Junho/ 2016, pp. 425-454. Disponível em: http://www.scielo.br/scielo.php?pid=S003476122016000300425\&script=sci_abstract\&tlng=pt. Acesso em: 05/maio/2018.

MINGOTI, Sueli Aparecida (2005). Análise de dados através de métodos de estatística multivariada: uma abordagem aplicada. Belo Horizonte: Editora UFMG, 2005.

PROJECT MANAGEMENT INSTITUTE (2014). Project Management Body of Knowledge - Um guia do conjunto de conhecimentos em gerenciamento de projetos. 2014, $6^{\text {a }}$ edição. 
SUZIGAN, Wilson. (2006). Identificação, mapeamento e caracterização estrutural de Arranjos Produtivos Locais no Brasil. Relatório Consolidado. Diretoria de Estudos Setoriais (DISET), Instituto de Pesquisa Econômica (IPEA). Disponível em: http://www3.eco.unicamp.br/neit/images/destaque/Suzigan_2006_Mapeamento_Identifi cacao_e_Caracterizacao_Estrutural_de_APL_no_Brasil.pdf. Acesso em: 05/maio/2018.

SUZIGAN, Wilson; GARCIA, Renato; FURTADO, João; SAMPAIO, S.E.K (2003). Sistemas Locais de Produção: mapeamento, tipologia e sugestões de política. Texto apresentado no XXXI Encontro Nacional de Economia - Porto Seguro, BA, 09 a 12 de dezembro de 2003.

Disponível em:

http://www.anpec.org.br/encontro2003/artigos/E28.pdf

TATSCH, Ana Lúcia; BOTELHO, Marisa dos Reis A.; MATOS, Marcelo Pessoa (2017). Arranjos Produtivos Locais como instrumento de promoção do desenvolvimento local e regional: as experiências do Sul e Sudeste. In: MATOS, Marcelo Pessoa; CASSIOLATO, José Eduardo; LASTRES, Helena M. M; LEMOS, Cristina; SZAPIRO, Marina. Arranjos Produtivos Locais - Referencial, experiências e políticas em 20 anos da RedeSist. Rio de Janeiro: E-papers, 2017, $1^{\text {a }}$ edição, pp. 371-391. 